\title{
Effectiveness of "Information Package for Antenatal Care" on Maternal and Fetal Outcome among High Risk Mothers Attending Antenatal Clinic (ANC), PGIMER, Chandigarh 2018-20
}

\author{
Mamta $^{1}$, Sukhjit Kaur ${ }^{2}$, Anju Singh ${ }^{3}$, Rupinder Kaur ${ }^{4}$ \\ ${ }^{1}$ MSc. Nursing 2nd Year, National Institute of Nursing Education, PGIMER, Chandigarh \\ ${ }^{2}$ Nursing Tutor, National Institute of Nursing Education, PGIMER, Chandigarh \\ ${ }^{3}$ Assistant Professor, Dept. of obstetrics and Gynecology. \\ ${ }^{4}$ Nursing Tutor, National Institute of Nursing Education, PGIMER, Chandigarh \\ Corresponding Author: Mamta
}

DOI: https://doi.org/10.52403/ijhsr.20220229

\begin{abstract}
Pregnancy with high risk conditions is threatening the life of the mother as well as fetus. Early detection and immediate intervention are necessary to prevent the maternal and fetal complications. This study assessed the effectiveness of information package on maternal and fetal outcome in high risk mothers.

Objective: The objective of the study was to assess the effectiveness of "information package for antenatal care" on maternal and fetal outcome among high risk mothers.

Material and Methods: Pre-experimental design was used where total 200 antenatal mothers were enrolled by purposive sampling technique. Data were collected by using interview schedule in the period of July to December2019. An assessment proforma were used for the assessment of antenatal mothers with high risk conditions regarding maternal and fetal outcome. After initial assessment, Information package for antenatal care were implemented by educating mother regarding routine antenatal care including special care for high risk conditions. They were educated by one to one basis by using booklet "Information package for antenatal care". Clinical diary were given to record their activities regarding weight, blood pressure, blood sugar monitoring, diet, schedule of supplement and prescribed medicine, exercises, Daily fetal movement count etc. After intervention, Assessment of Antenatal mother were done accordingly as per schedule of antenatal visit till discharge.

Results: The results of the study reveals that Hemoglobin level $(\mathrm{Hb})$ level, Post-prandial blood sugar level and Thyroid stimulating hormone level (TSH) was improved in antenatal mother with Anaemia, Gestational diabetes mellitus and hypothyroidism respectively after intervention of information package for antenatal care .

Conclusion: It was concluded that information package for antenatal care is effective to improve haemoglobin level, blood sugar level, Thyroid stimulating hormone level in antenatal mother with Anaemia, Gestational diabetes mellitus and hypothyroidism respectively.
\end{abstract}

Keywords: Maternal outcome, fetal outcome, Gestational diabetes mellitus.

\section{INTRODUCTION}

Pregnancy is an inimitable, stirring, and joyful time in a women's life as it express the woman's incredible, innovative and fostering powers while providing a link to the future. It brings a new sense to the thought of beauty and this time a woman cherishes with enormous joy and anticipation. The emotion of carrying in a little soul within in her is glorious. A baby 
fills a peace in the mother's heart that she never knew was empty. ${ }^{1}$ Each week of pregnancy brings with a new changes and thoughts that may require some explanations and hold up to the pregnant woman. It is the period during which a baby is in the mother's womb for about 280 days. Progression of both physiological and psychological changes occur during pregnancy. ${ }^{2}$

A pregnant woman passes through period of pregnancy, labor and puerperium, it is important to provide antenatal, Intranatal and postnatal care. All pregnancy must be identified for high risk factors. High risk factors includes obstetric factors- Grand multipara, Age less than 18years and more than 35 years ,Height less than $145 \mathrm{~cm}$, multipara with bad obstetric history like( loss of baby, cesarean section ,Hypertension in previous pregnancy, recurrent premature labour and abortion, Intrauterine growth retardation), case of disproportion, Malpresentation, multiple pregnancy, obstetric complications includes hemorrhage during pregnancy (threatened abortion, Antepartum hemorrhage), pregnancy induced hypertension (Preeclampsia, eclampsia), high risk fetus (premature labor, RH incompatibility fetus, post maturity, intrauterine growth retarded fetus). Medical factors include (anemia and malnutrition, cardiac diseases (pulmonary tuberculosis, hepatitis, syphilis, psychiatric disorders, thyroid disorders and others), social factors include unwed pregnancy, no or less than 3 antenatal checkup or low socioeconomic group. In western countries this incidence of high risk pregnancy comes to about one third in all the pregnancies. This incidence can be seen at least double numbers, because of anemia, under nutrition poor social factors and parity. ${ }^{3}$

Each pregnancy has three trimesters. First trimester is first 12 weeks of pregnancy, second trimester starts from 13 weeks to 28 weeks and third trimester starts from 29 weeks to 40 weeks of pregnancy. If the baby born before completing the 37 weeks is considered premature. The first trimester is the most essential for the development of a fetus. A women's body goes through many changes during the first 12 weeks of gestation. Body structure and organ systems of the baby develop during this period. Most miscarriages and birth defect can be seen during this period. ${ }^{4}$ During $2^{\text {nd }}$ trimester, nausea and vomiting usually resolve, there are fewer complications can occur like pregnancy induced hypertension, diabetes mellitus, Oligohydromnia, Polyhydromnia, anemia, cardiac diseases, abortion. During third trimester, various complications can arise like Gestational diabetes, preeclampsia, preterm labour, premature rupture of membrane, intrauterine growth retardation; malpresentation. ${ }^{5}$ At present, no commonly established definition of high risk pregnancy occur. High risk pregnancy refers to pregnancy where complications are faced by the mother and her unborn child and also it will affect the life of both mother and baby.

Pregnancy checkup is necessary for at least ten times in case of high risk pregnant women and five times in case of normal pregnancies ${ }^{6}$. Prenatal assessment and screening of high risk cases through antenatal assessment, review lab orders/investigations, obtaining Ultrasonography report, identification of high risk and follow up prevent the complication of high risk pregnancy.

Approximately, 830 women dies every day from preventable causes which are associated with pregnancy and childbirth. In developing countries, nearly $99 \%$ of the death of the mothers occurs. Pregnant women who are living in rural areas and poorer communities, mortality rate is seen higher. Higher risk of maternal complications and death faced by young adolescents than other women. So, the lives of the women and newborn babies can be saved by providing skilled care before, during and after childbirth. Worldwide, maternal mortality has been dropped by 44\% during the year 1990 and 2015. The year 2016 and 2030, is considered as the Sustainable Development Goals, where the 
target is to reduce MMR to less than 70 per 100000 live births globally. ${ }^{7}$ According to study, there is $20-30 \%$ high risk pregnancies in India which leads to $75 \%$ of perinatal mortality and morbidity. So, for the reduction of maternal mortality, it is necessary to detect high risk pregnancy and their management in early stage. ${ }^{8}$

Each year, globally 529,000 women and girls die due to complications associated with pregnancy. Most of the complications are preventable with preventive measures. "National Institute of Child Health and Human Development" is national agencies who are working to improve pregnancy outcomes and recover health outcomes for pregnant women who are at risk. ${ }^{2}$

\section{MATERIAL AND METHOD}

Total 200 antenatal mothers were enrolled by purposive sampling technique and pre-experimental study design was used. Data were collected by using interview schedule in the period of July to December2019. The tool was prepared based on extensive review of relevant literature and consultation with experts from National Institute Of Nursing Education, Department Of Obstetrics And Gynecology, Physiotherapy And Dietetics Department. After validation, the needed changes were incorporated and tool was given for translation. Written Permission was obtained from Head of department, Obstetrics and gynecology, PGIMER, Chandigarh. Ethical approval was taken from institute ethics committee, PGIMER, Chandigarh vide no. NK/5163/Msc/10.

Antenatal women with high risk conditions were approached during their clinical visit in antenatal clinic, outpatient department (OPD). Women were informed about the purpose of the study and written consent was taken from her. A structured interview schedule was used to gather information regarding identification data. An assessment proforma were used for the assessment of antenatal mothers with high risk conditions regarding maternal and fetal outcome.
After Preassessment at initial visit, all the high risk mothers were educated regarding brief introduction about high risk conditions, routine antenatal care include personal hygiene, rest and sleep, precautions in travelling, medicine adherence, weight recording, daily fetal movement count, exercise, minor disorders during pregnancy, special care related to high risk conditions, preparation of labour and immediate postnatal care. Antenatal mothers were reassessed subsequently as per schedule of antenatal visit till delivery. Assessment proforma includes $\mathrm{Hb}$ level, TSH level, systolic and diastolic blood pressure, and urine testing for albumin and sugar, fasting and post-prandial blood sugar level, vaginal bleeding, amniotic fluid index, fetal heart rate. Telephonic follow-up was also done to reinforce the antenatal mothers for life style modifications. Addition to that antenatal mothers were assessed regarding duration of labour, mode of delivery, assessment of newborn regarding birth weight of the baby, respiratory distress syndrome, any congenital anomalies, physiological jaundice, duration of stay of mother and baby and condition of the mother and baby at discharge.

Analysis was done for 200 samples to assess the effectiveness of information package for antenatal care on maternal and fetal outcome among high risk mothers. The data was examined by statistical analysis such as descriptive statistics includes frequency, percentage, and standard mean deviation. In inferential statistics that were used in the study included chi square test.

\section{RESULTS}

Table1 (a) illustrate the assessment of high risk mother in initial visit and subsequent follow-up during antenatal period. In Preassessment, Majority (91\%) of antenatal mothers had mild anaemia. It was observed that Haemoglobin level was improved in subsequent follow up. Majority $(93 \%)$ of the antenatal mother had fasting blood sugar level more than $95 \mathrm{mg} / \mathrm{dl}$ and $63 \%$ of the mother had post prandial blood 
sugar level more than $126 \mathrm{mg} / \mathrm{dl}, 17.5 \%$ and $7 \%$ had presence of ketone and albumin in urine respectively. It was progressing to normal in subsequent follow-ups. More than $50 \%$ of the antenatal mother had systolic blood pressure between 120 to129 $\mathrm{mm} \mathrm{Hg}$; it was improved in the subsequent follow up. Further table reveals that $17 \%$ of the mother had systolic blood pressure more than $140 \mathrm{~mm} \mathrm{Hg}$, it was within the normal range in First and second follow-up but in third visit. $7 \%$ of the antenatal mother had high blood pressure. In relation to diastolic blood pressure, $43 \%$ of mother had more than $90 \mathrm{mg} / \mathrm{dl}$; it was improved in subsequent follow-up. 10\% and 3\% of the antenatal mother had presence of sugar and albumin in urine respectively. It is pleasant to note that none of the mother had albuminuria and ketonuria after intervention.65\% of the antenatal mother had high TSH level, it was observed that TSH level was improved in subsequent follow-up.

Table: 1(a): Assessment of High risk mothers in Initial visit and Subsequent follow-up during Antenatal Period. N-20

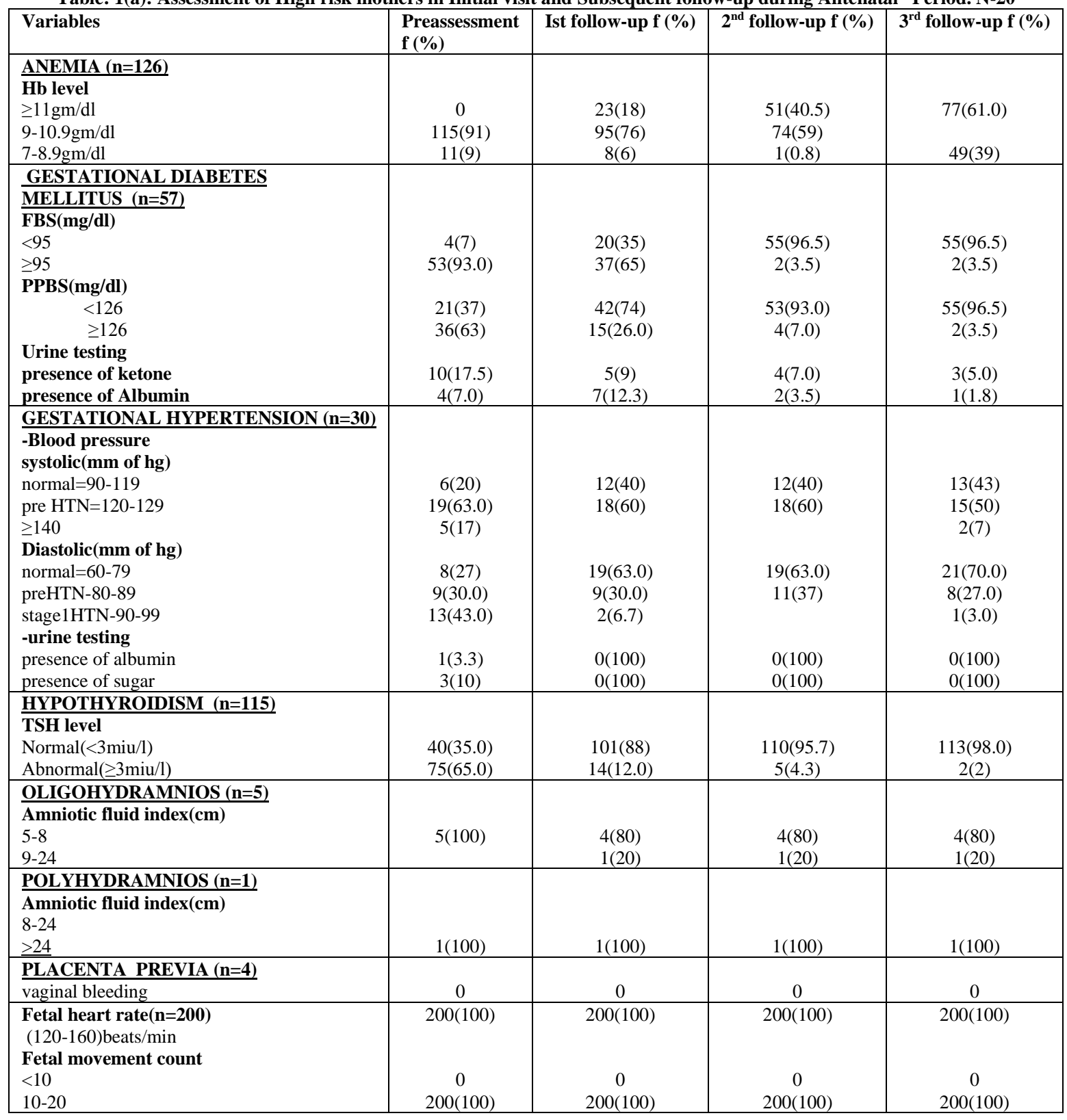

Table 1(b) reveals that $91.5 \%$ mothers had normal vaginal delivery and
$10 \%$ had prolonged labor i.e. more than 18 hrs, $8.5 \%$ had Lower segment caesarean 
Mamta et.al. Effectiveness of "information package for antenatal care" on maternal and fetal outcome among high risk mothers attending antenatal clinic (ANC), PGIMER, Chandigarh 2018-20.

section delivery. It is pleasant to note that, All the antenatal mothers with normal vaginal delivery had passed urine with in $1 \mathrm{hr}$ after delivery and discharged within 3 days. All the antenatal mothers who were having caesarean section delivery had passed urine with in $1 \mathrm{hr}$ after removal of catheter and had discharged within 7 days.

Table: 3 (b): Assessment of High risk mothers during Intranatal and postnatal period on Maternal outcome $\mathbf{N}=200$

\begin{tabular}{|c|c|}
\hline Variables & High risk mothers, $\mathbf{f}(\%)$ \\
\hline $\begin{array}{l}\text { Type of delivery } \\
\text { Normal vaginal delivery } \\
\text { Lower segment caesarean section delivery }\end{array}$ & $\begin{array}{l}183(91.5) \\
17(8.5)\end{array}$ \\
\hline $\begin{array}{l}\text { Normal vaginal delivery }(\mathrm{n}=183) \\
\text { Primigravida } \\
\text { Multigravida }\end{array}$ & $\begin{array}{l}101(55) \\
82(45)\end{array}$ \\
\hline $\begin{array}{l}\text { Lower segment caesarean section delivery }(\mathrm{n}=17) \\
\text { Primigravida } \\
\text { Multigravida }\end{array}$ & $\begin{array}{l}14(82) \\
3(18)\end{array}$ \\
\hline $\begin{array}{l}\text { Normal labour } \\
\text { For primigravida }(n=101)\end{array}$ & \\
\hline $\begin{array}{l}\text { Ist stage } \\
<12 \mathrm{hrs} \\
>12 \mathrm{hrs}\end{array}$ & $\begin{array}{l}93(92) \\
8(8)\end{array}$ \\
\hline $2^{\text {nd }}$ stage & $98(97)$ \\
\hline$<2 \mathrm{hrs}$ & $3(3)$ \\
\hline $\begin{array}{l}>2 \mathrm{hrs} \\
3^{\text {rd }} \text { stage }\end{array}$ & 100(99) \\
\hline$<30 \mathrm{~min}$ & $1(1)$ \\
\hline$>30 \mathrm{~min}$ & \\
\hline For multigravida $(\mathrm{n}=82)$ & \\
\hline Ist stage & $69(84)$ \\
\hline$<6 \mathrm{hrs}$ & $13(16)$ \\
\hline$>6 h r s$ & \\
\hline $2^{\text {nd }}$ stage & $77(94)$ \\
\hline$<1 \mathrm{hr}$ & $5(6)$ \\
\hline$>1 \mathrm{hr}$ & \\
\hline $3^{\text {rd }}$ stage & $80(98)$ \\
\hline$<15 \mathrm{~min}$ & $2(2)$ \\
\hline $\begin{array}{l}>15 \mathrm{~min} \\
\text { prolonged labour }\end{array}$ & $20(10)$ \\
\hline Urine passed with in 1 hour in normal vaginal delivery & $183(100)$ \\
\hline Urine passed with in 1 hour after removal of catheter in LSCS & $17(100)$ \\
\hline $\begin{array}{l}\text { Duration of stay at hospital in case of } \mathrm{NVD}(\mathrm{n}=183) \\
\text { Mother } \\
\leq 3 \text { days }\end{array}$ & $183(100)$ \\
\hline $\begin{array}{l}\text { Duration of stay at hospital in case of cesarian } \operatorname{section}(\mathrm{n}=17) \\
\text { Mother } \\
\leq 7 \text { days }\end{array}$ & $17(100)$ \\
\hline
\end{tabular}

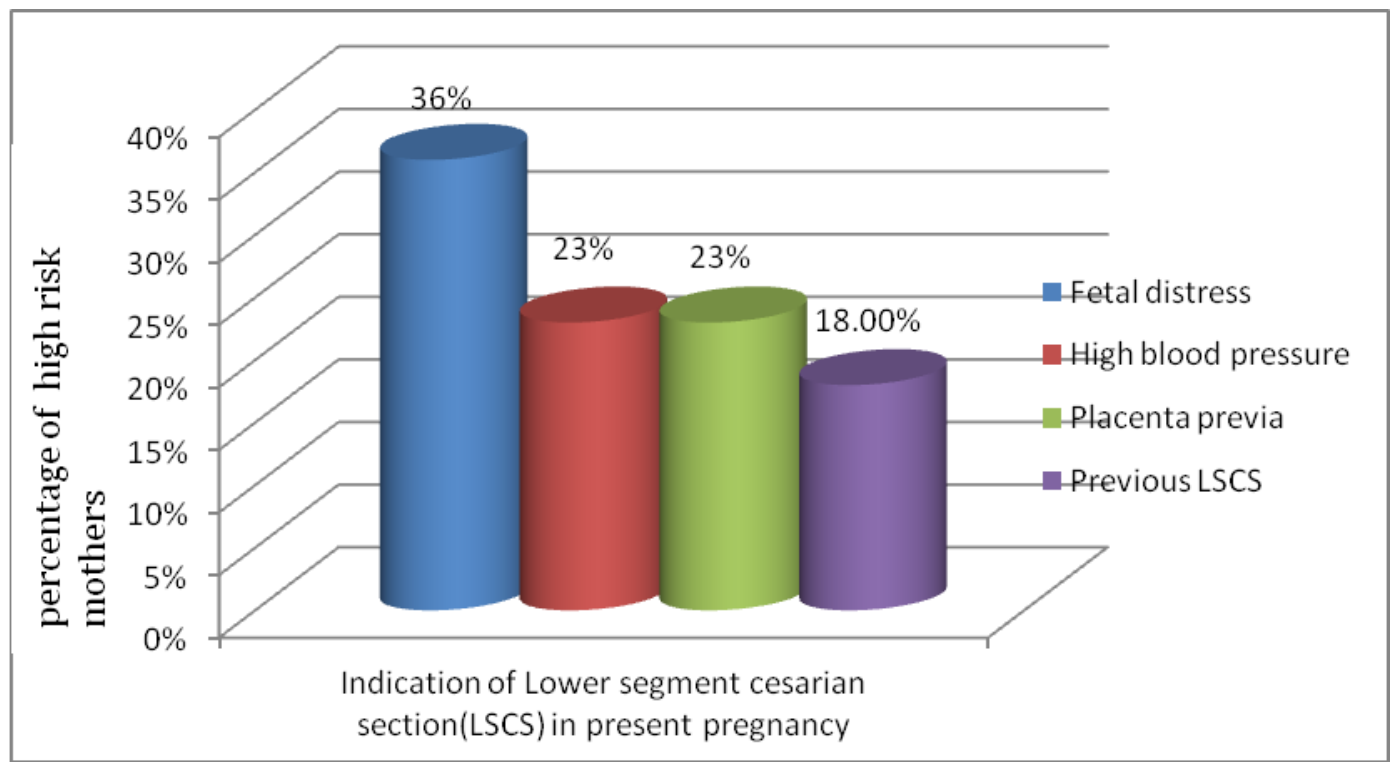

Figure1 depicts the Indication of Lower segment caesarean section. $\mathrm{N}=17$ 
More than one third of the mother had lower segment caesarean section delivery (LSCS) due to fetal distress. Equal number $(23 \%)$ of the women, due to high blood pressure and placenta previa.18\% had caesarean section due to, previous caesarean section.

Table 1(c) depicts Assessment of high risk mothers during Intranatal period on fetal outcome. Majority of the Antenatal mothers had baby with normal birth weight. Only $2 \%$ of the babies stay in the Neonatal intensive care unit (NICU) for more than 3 days due to physiological jaundice and respiratory distress syndrome.
Table1(c): Newborn assessment of mother with high risk conditions. $\mathbf{N}=\mathbf{2 0 0}$

\begin{tabular}{|l|l|}
\hline Variable & $\begin{array}{l}\text { High risk mothers } \\
\text { f(\%) }\end{array}$ \\
\hline Birth weight of baby(n=200) & $140(70)$ \\
Normal & $55(27.5)$ \\
Low birth weight baby & $5(2.5)$ \\
\hline Very low birth weight baby & $157(78.5)$ \\
\hline $\begin{array}{l}\text { Sex of the baby } \\
\text { boys } \\
\text { girl }\end{array}$ & $43(21.5)$ \\
\hline $\begin{array}{l}\text { Duration of stay at hospital in case of } \\
\text { Normal vaginal delivery }\end{array}$ & $\mathrm{n}=183$ \\
$\begin{array}{l}\text { Baby } \\
\leq 3 \text { days }\end{array}$ & $179(89.5)$ \\
$\begin{array}{l}\text { More than 3days } \\
\text {-Indication of staying in hospital } \\
\text { physiological jaundice } \\
\text { Respiratory distress }\end{array}$ & $4(2.0)$ \\
\hline $\begin{array}{l}\text { Duration of stay at hospital in case of } \\
\text { caesarean section }\end{array}$ & $3(1.5)$ \\
$\begin{array}{l}\text { Baby } \\
\leq 7 \text { days }\end{array}$ & $1(0.5)$ \\
\hline
\end{tabular}

Table1 (d): Effectiveness of information package on high risk mothers in relation to maternal outcome during antenatal period. $\mathbf{N}=\mathbf{2 0 0}$

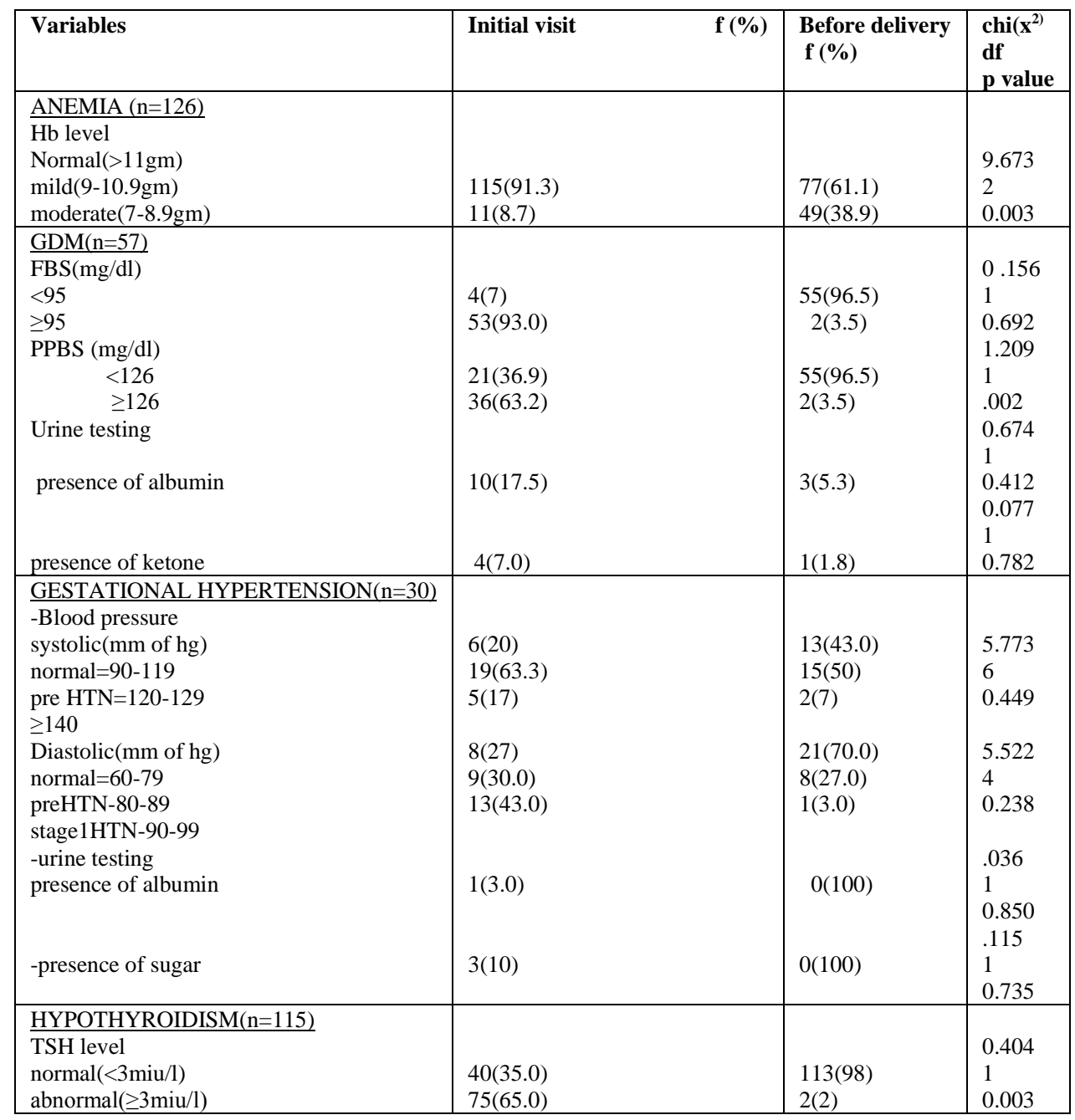

Table 1(d) shows the effectiveness of information package on high risk mothers in relation to maternal outcome during antenatal period. In Preassessment, Majority
$(91 \%)$ of antenatal mothers had mild anaemia. It was observed that Haemoglobin level was improved in subsequent follow up. $93 \%$ of the antenatal mother had fasting 
blood sugar level more than $95 \mathrm{mg} / \mathrm{dl}$ and $63 \%$ of the mother had post prandial blood sugar level more than $126 \mathrm{mg} / \mathrm{dl}$, less than $18 \%$ had ketone and albumin in urine. It was progressing to normal in subsequent follow-ups. In mother with Gestational hypertension, $10 \%$ and $3 \%$ had presence of sugar and albumin in urine respectively. None of the mother had albuminuria and ketonuria after intervention. More than half of the antenatal mother had high TSH level, it was observed that TSH level was improved in subsequent follow-up. Chi square was applied to see the significant difference between the initial visit and before delivery as the $p$ value is $<0.05$. This difference of maternal outcome was found statistically significant in antenatal women with anaemia, Gestational diabetes mellitus in relation to post-prandial blood sugar level and women with hypothyroidism except Gestational hypertension.

\section{DISCUSSION}

High risk pregnancy can affect the health of mother or baby and complications are faced by the mother and her unborn child. If initially detection and effective management of high risk pregnancy can considerably be helpful for the reduction of maternal and neonatal mortality and morbidity rate. Present study was conducted with the objective to evaluate the effectiveness of information package for antenatal care among high risk mothers on maternal and fetal outcome attending Antenatal Clinic out Patient Department PGIMER, Chandigarh. Two hundred women who fulfilled the inclusion criteria were chosen as subjects using purposive sampling technique from Antenatal OPD, Obstetrics and Gynecology department of PGIMER, Chandigarh. The study was conducted from the month of July to December 2019. The collected data was analyzed using SPSS version 2.0, descriptive and inferential statistics were used for analyzing the data.

Findings of the present study reveals that Information package for antenatal care had effect in improvement of Haemoglobin level, blood sugar level, Thyroid stimulating hormone level in antenatal mother with Anaemia, Gestational diabetes mellitus and hypothyroidism respectively $(\mathrm{p}<0.05)$, which helped in improving the positive outcome of pregnancy. The results of the studies are accordance with our study. These studies by Noran M. Abu ouf et.al, on the impact of maternal iron deficiency anemia on child's health, they strongly recommend the need of iron supplementation. ${ }^{9}$ Study done by Lindsay $\mathrm{H}$ Allen on anemia and iron deficiency effect on pregnancy outcome ${ }^{10}$, by Mishra $\mathrm{S}^{11}$, by Antonia regynara moreira rodrigues1, et.al ${ }^{12}$, by Brittany M. Byerley et.al ${ }^{13}$ to evaluate the effect of good antenatal care to high risk conditions have shown similar results. They emphasis the need of early detection, prompt initiation of treatment, adequate follow-up and most important ,sufficient education of the patients regarding the importance of the condition for prompt management. Similar study conducted by Rakesh Kumar Sahay reveals that medication adherence and regular follow up is most important for managing the hypothyroidism during pregnancy ${ }^{14}$. Findings were consistent with the study conducted by Rodica Tudosa that prenatal care improve the health outcomes for both mothers and babies. ${ }^{15}$ Results were also parallel with the study done by Dorothy Brooten, that careful monitoring and early treatment can prolonged gestation period to reduce preterm delivery.

Present study shows that All the antenatal women who were height $<145 \mathrm{~cm}$, had normal vaginal delivery. Study conducted by Rusleena Toh-adam Tongsong on Short stature as an independent risk factor for cephalopelvic disproportion. They concluded that $70 \%$ operative vaginal delivery and $22 \%$ cesarean section are due to relatively small sized mothers. They found mothers with short stature were significantly correlated with a higher rate of cephalopelvic disproportion. ${ }^{15}$ 
Finding of the present study also reveals that majority $(63 \%)$ of the antenatal women had anemia and $25 \%$ with anemia had low birth weight babies. Findings were consistent with the study conducted by Grace Stephen, Emmanueli Msuya on Prevalence, Risk Factors, and Adverse Perinatal Outcomes of anemia in Northern Tanzania. They found the prevalence of anemia was $18.0 \%$. Forty women had mild, 43 moderate and 12 had severe anemia and they deliver 10 stillbirths, 16 low birth weight (LBW) newborns, and 2 preterm birth cases ${ }^{16}$.

In the present study, More than $80 \%$ of the mother delivered vaginally, who were having the history of previous caesarean section. Similar findings were noted by Lekshmi Balachandran et al. Among 151 women, 115 were trial of scar. Of them, 96(83.47\%) had vaginal birth after cesarean section and $19(16.5 \%)$ had a repeat cesarean section. They concluded that trial of labour after prior cesarean is safe and often successful. A prior vaginal birth after cesarean are associated with higher rate of successful trial of labour. ${ }^{18} \mathrm{G}$ Singh et.al on bad obstetric history also recommended that pregnancy outcome was generally good in subsequent pregnancies with optimal antenatal care and advice. ${ }^{17}$

Finding of the study concluded that Haemoglobin level, fasting blood sugar level and Thyroid stimulating hormone level was improved after intervention of information package during antenatal period. Majority (91.5\%) of the mother had normal vaginal delivery, only $10 \%$ had prolonged labour and $30 \%$ give birth to low weight babies Majority of the mother and baby discharged with in time according to hospital policy.

Hence, information package for antenatal care had effect in improvement of Hemoglobin level ,blood sugar level, Thyroid stimulating hormone level in antenatal mother with Anaemia, Gestational diabetes mellitus and hypothyroidism respectively $(\mathrm{p}<0.05)$, which helped in improving the positive outcome of pregnancy.

\section{CONCLUSION}

The pregnancies are generally at risk even though maximum pregnancies and child birth around worldwide are uneventful. Finding of the study concluded that highest percentage of antenatal women $(63 \%)$ was with anemia followed by Hypothyroidism. Haemoglobin level, postprandial blood sugar level and Thyroid stimulating hormone level was improved after intervention of information package during antenatal period. Majority $(91.5 \%)$ of the mother had normal vaginal delivery, only $10 \%$ had prolonged labour and 30\% gave birth to low weight babies Majority of the mother and baby discharged with in time according to hospital policy.

It can be concluded that information package for antenatal care had effect in improvement of Hemoglobin level ,blood sugar level, Thyroid stimulating hormone level in antenatal mother with Anaemia, Gestational diabetes mellitus and hypothyroidism respectively ( $\mathrm{p}<0.05)$, which helped in improving the positive outcome of pregnancy.

\section{Acknowledgement: None}

Conflict of Interest: None

\section{Source of Funding: None}

\section{Ethical Approval: Approved}

\section{REFERENCES}

1. (Introduction to Pregnancy - Pregnancy [Internet]. [cited 2019 Feb 3]. Available from:

https://www.centersite.net/poc/view_doc.ph p?type $=$ doc\&id $=6129$

2. High-risk pregnancy. In: Wikipedia [Internet]. 2019 [cited 2019 Feb 3]. Available from: https://en.wikipedia.org/w/index.php?title= High-risk_pregnancy\&oldid=879195131 
3. Dawn C.S, Rule of Ten $\mathrm{MCH}$ care and education, uterine maturity score, textbook of obstetrics current edition Calcutta 1986.

4. What are symptoms of complications during the first trimester of pregnancy? | 1st Trimester Of Pregnancy [Internet]. Sharecare. [cited 2019 Feb 10]. Available from:

https://www.sharecare.com/health/1sttrimester-of-pregnancy/what-symptomscomplications-first-trimester.

5. The Second Trimester of Pregnancy: Complications [Internet]. [cited 2019 Feb 10]. Available from: https://www.healthline.com/health/pregnanc $\mathrm{y} /$ second-trimester-complications.

6. WHO. Maternal mortality [Internet]. [cited 2019 Feb 6]. Available from: https://www.who.int/news-room/factsheets/detail/maternal-mortality.

7. Pradeep MK, Gnanadeep NV, Umesh RD, Pushpa SP. Prevalence of high risk pregnancy in rural dharwad. Iosr journal of dental and medical sciences. 2015

8. Global Issues - Feminist Majority Foundation [Internet]. [cited 2019 Feb 3]. Available from: http://www.feminist.org/global/gsrhr.html).

9. Abu-Ouf NM, Jan MM. The impact of maternal iron deficiency and iron deficiency anemia on child's health. Saudi Med J. 2015;36(2):146-9.

10. Allen LH. Anemia and iron deficiency: effects on pregnancy outcome. Am J Clin Nutr. 2000 May;71(5 Suppl):1280S-4S. doi: 10.1093/ajcn/71.5.1280s. PMID: 10799402.

11. Sunita M, Rajesh K . Effect of antenatal care on pregnancy induced hypertension. (2013).Available form: https://www.researchgate.net/publication/27 0525141 Effect of antenatal care on pregnancy induced hypertension.
12. Rodrigues ARM, Rodrigues DP, Viana AB, Cabral L da S, Silveira MAM da. Nursing care in high-risk pregnancies: an integrative review. Online Brazilian Journal of Nursing. 2016 Sep 27;15(3):472-83.

13. Byerley BM, Haas DM. A systematic overview of the literature regarding group prenatal care for high-risk pregnant women. BMC Pregnancy and Childbirth. 2017 Sep 29;17(1):329.

14. Sahay RK, Nagesh VS. Hypothyroidism in pregnancy. Indian $\mathrm{J}$ Endocrinol Metab. 2012;16(3):364-70.

15. Toh-adam R, Srisupundit K, Tongsong T. Short stature as an independent risk factor for cephalopelvic disproportion in a country of relatively small-sized mothers. Arch Gynecol Obstet. 2012 Jun;285(6):1513-6.

16. Stephen G, Mgongo M, Hussein Hashim T, Katanga J, Stray-Pedersen B, Msuya SE. Anaemia in Pregnancy: Prevalence, Risk Factors, and Adverse Perinatal Outcomes in Northern Tanzania. Anemia [Internet]. 2018 May 2 [cited 2020 Mar 28];2018. Available from:

https://www.ncbi.nlm.nih.gov/pmc/articles/ PMC5954959/

17. Singh G, Sidhu K. Bad Obstetric History: A Prospective Study. Med J Armed Forces India. 2010 Apr;66(2):117-20.

18. Balachandran L, Vaswani PR, Mogotlane R. Pregnancy Outcome in Women with Previous One Cesarean Section. J Clin Diagn Res. 2014 Feb;8(2):99-102.

How to cite this article: Mamta, Kaur S, Singh A et.al. Effectiveness of "information package for antenatal care" on maternal and fetal outcome among high risk mothers attending antenatal clinic (ANC), PGIMER, Chandigarh 2018-20. Int J Health Sci Res. 2022; 12(2): 204212. DOI: https://doi.org/10.52403/ijhsr. 20220229 